\title{
AC 2007-2598: A METHODOLOGY FOR ASSIGNING PROJECT TEAMS
}

\section{Hugh Jack, Grand Valley State University}

Hugh Jack is the Chair of Product Design and Manufacturing Engineering at Grand Valley State University in Grand Rapids Michigan. His interests include controls, automation, and open source software. 


\title{
A Methodology for Assigning Project Teams
}

\begin{abstract}
Why do we use team based projects when we teach? In part it is because we want students to apply new knowledge beyond structured homework problems. The benefit of working in a team is that each team member can contribute towards a common goal and achieve more than one could individually. And, after graduation, our students will work as part of a team on many projects.

How are student teams usually made? When the students are allowed to group themselves the results are clusters of friends, interspersed with human filler. When grouped by instructor the teams can be designed to distribute strengths and weaknesses across all teams evenly to ensure even chances of success. Methods to categorize strengths and weaknesses can be as simple as grades ${ }^{1}$, or as complex as personality indicators. When personality indicators are used the teams are designed to have complimentary personalities.

What makes a team successful or fail? A team that functions well will approach a task and produce strong results without 'issues'. Some teams will be pulled off track by conflicts with an individual and produce sub-optimal solutions. Teams that are largely non-functional will simply fail because of widespread personality conflicts. Essentially, conflicts impact the team performance. Issues that tend to lead to major conflicts on student teams include but are not limited to a lack of motivation, lack of talent, working too much, and abrasive personalities.

The topics of personality and conflicts must be dealt with separately when forming teams, with conflicts being given the higher priority. This paper describes a method for forming project teams that can be copied or modified for use in other courses. In simple terms the method can be described as "Group students on teams with similar challenges, and everybody will benefit".
\end{abstract}

\section{Introduction}

The engineering program at Grand Valley State University has a strong industrial focus. In support of our mission, projects have always been used extensively throughout the curriculum. The project process begins in the freshman year using formalized project management experiences for the students, and management procedures for the faculty. The typical sequence for a project is given below ${ }^{2}$.

1. Team formation

2. Needs identification

3. Conceptual designs

4. A detailed design proposal

5. Approval

6. Build, test, and debug 


\section{Signoff or final approval}

Over the many years of managing projects we have identified factors that lead to project success and failure. The first important question is 'what makes a project successful?' One way to answer the question is to choose the right 'recipe'.

- the right team

- the right preparation and skills set

- a project with the right scope

- suitable resources

- project oversight

Another way to answer the question is to look at the outcomes: it is successful 'If it meets all of the objectives.' From the perspective of the student the objective is a working project (and a good grade). From the faculty perspective we are looking at what the students have gained or if they can demonstrate new knowledge. These objectives do have their parallels to industry, but there are some important differences. For example if an industrial project fails there can be major repercussions. However, if a student project fails it can often provide an excellent learning opportunity.

In industry (engineering) teams are used to allow multiple professionals to split tasks for specialization or time reasons. They work concurrently with occasional checkpoints for synchronization. However the students' perspective varies somewhat. When students arrive at first they have a variety of approaches and understandings about projects. Table 1 shows the level of expectation for students as they progress through the curriculum. As they enter their senior year they should be proficient with project work to ensure a successful senior project.

Table 1: Project Management Expectations

\begin{tabular}{|l|l|l|l|l|}
\hline \multicolumn{1}{|c|}{ Skill } & Freshman & Sophomore & \multicolumn{1}{|c|}{ Junior } & \multicolumn{1}{|c|}{ Senior } \\
\hline \hline follow a timeline & High & High & High & High \\
\hline plan a timeline & Low & Medium & Medium & High \\
\hline identify a design problem & Low & Low & Medium & High \\
\hline formulate a problem statement & Low & Medium & Medium & High \\
\hline develop specifications & Low & Low & Medium & High \\
\hline interact with customers & Low & Low & Medium & High \\
\hline communicate professionally & Low & Medium & High & High \\
\hline generate design concepts & Low & Low & Medium & High \\
\hline select design concepts & Low & Low & Medium & High \\
\hline track budgets & Low & Low & Medium & High \\
\hline
\end{tabular}


When done formally, project team composition can be planned using methods such as the well known Myers-Briggs personality indicators. When applied to team formulation the theory is to create a team that is complimentary and functional. These methods can be very useful when forming professional teams with diverse disciplines and people ${ }^{3}$.

In an industrial setting a team may be selected from a larger group for a particular task. Key elements for teams are a common goal, clearly defined roles, a positive attitude, communication, and creating harmony. For want of a better term I will call this the team culture. In an industrial setting you need to pick a team from a larger group for a project. In an academic setting we must put all of our students on a team, hence we must deal with some individual 'cultural variations' that we would not normally have to choose in industry. However, we know that many of our students have not yet finished their transition to the role of 'professional'. To simply put them on a team and assume they are a professional is to overlook the much needed education in basic professionalism. As with any pedagogical method we have identified perpetual problems with problem students and specifically address these through project team design. The general categories that we encounter with students at our institution are listed below in relative frequency/importance. They have been developed using personal interactions during, and peer evaluations after student projects from a variety of courses and faculty. Each school will have a different list. For example, our list obviously excludes cultural differences.

- Working - Students working outside school 20 or more hours per week often have schedules that do not fit with regular full time students. In our case this is a quarter of the junior class.

- Overcommitted - These students have too many activities on-campus with sports, extracurricular clubs, or academics. Other students often have a difficult time trying to get together with them for project work.

- Personality - These students generally do not play well with others. They will often split a team, bully an individual, or in some cases fight with the entire team.

- Unmotivated/Untalented - For whatever reason these students traditionally hold back on project teams and let others carry the load. When these students are on a team with a 'Personality', they will often be used as the scapegoat for problems.

- Talented - These students have one or more attribute that makes them stand out from the crowd including skills (leadership/maturity, hands-on, theory). Other students often assume that 'talented' students are highly capable and defer high level decision making.

- General - Students that do not get set into one of the other categories can be lumped here. In general they will produce reliable results and form the body of a regular team.

The general process for managing team structures is shown in Figure 1 for a project that covers a 14 week semester. Naturally this can be adjusted for variable times. The elements in the flowchart are described in following sections. 


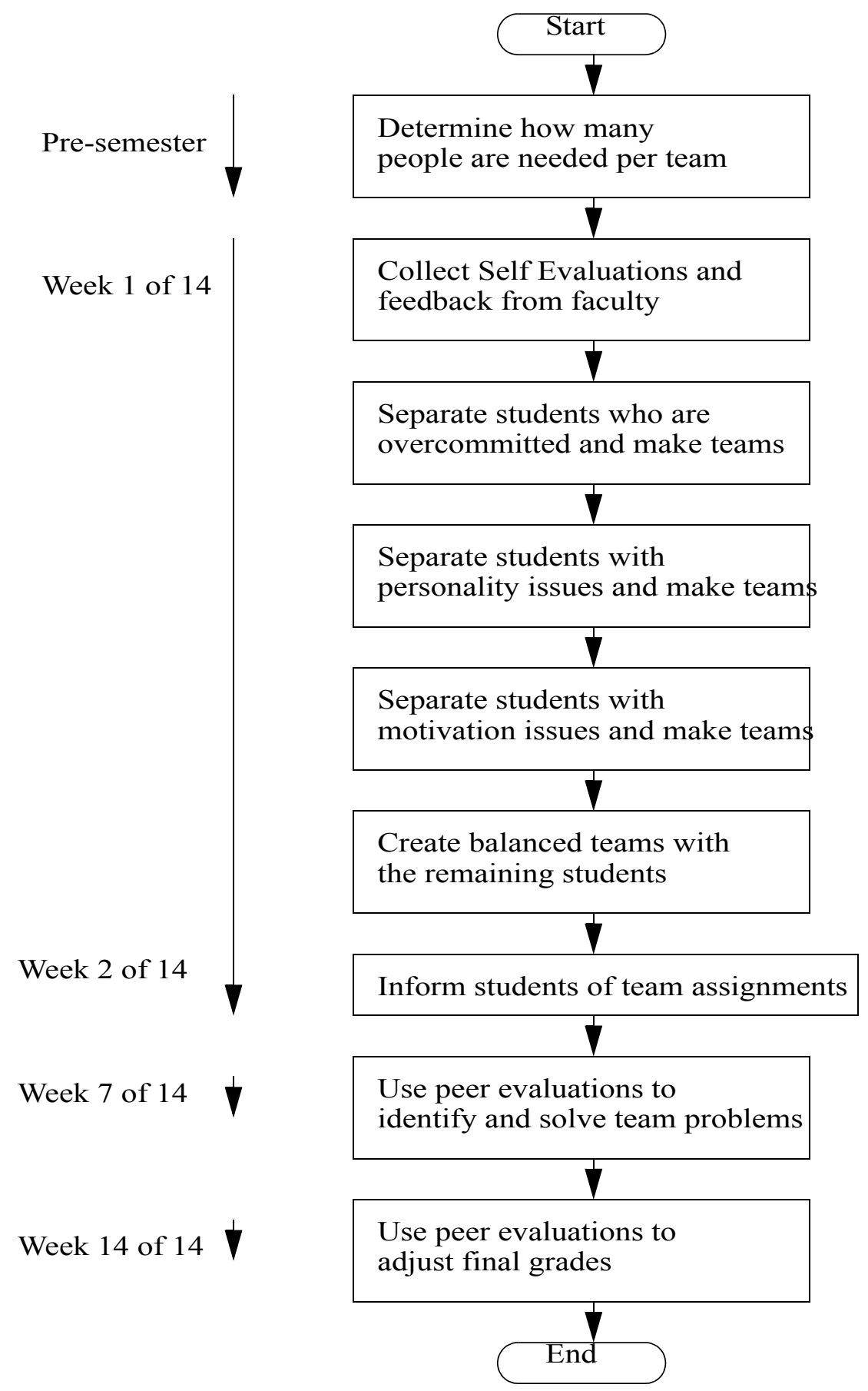

Figure 1 - Example of team management and allocation

\section{Choosing Team Sizes}

Assuming that a project of suitable scope has been chosen the instructor should consider the project and compare the minimum number of hours that would be required to complete the work 
to the number of hours expected per student. In cases where the components are substantially different this may require separate people. For example if there is a chassis and a separate throwing arm, two people may be required. When the time estimate is complete is should be used as the absolute minimum. A larger team must learn to overcome the communication issues involved with divided work ${ }^{4}$. Senior students are often more mature and able to adapt to larger teams, however lower level teams often require additional members to offset these inefficiencies. For example, for a sophomore/junior level team experience shows if the prediction calls for 2 minimum use a team of 3 , but if the estimate calls for 4 people use 6 or 7 . Adding the extra people provides for the added overhead of communication and added time needed for coordination.

\section{Self Evaluations}

The form shown in appendix A is used for a junior level mechanical and product design and manufacturing engineering course. Similar forms are used in other courses. The form is distributed and returned shortly after the first class of the semester. Typically the numerical scores on these forms are uniformly high, except for the hands-on skills. For example students reporting mathematical problem solving ability (3.73/5), leadership skills (average 3.79/5), and design skills (3.68/5) but very few say they are technically excellent (average /5). The scores for the hands-on skills are used when creating teams to ensure that each team has somebody capable of building the mechanical and electrical components. The most important lines on the forms are the free form questions about partner preferences. These are used to keep them from working with friends. However we do honor requests to keep students separated. The question about outside work commitments is used to group students who are working too much. The remainder of the freeform responses can sometimes be used to distribute the teams.

\section{Team Assignment}

When possible we discuss students with faculty who have taught them before to identify key personality types. In particular abrasive, talented, and unmotivated students. Obviously there is little useful information on the freshmen, but as they progress to the senior year the faculty become very knowledgeable about individual students.

Next, the students are grouped into teams generally focusing on the personality issues discussed before.

1. students who are over committed are grouped on teams. For example, if students are working 40 hours/week, they are grouped on teams first. Note: When these students are mixed on regular teams there are numerous scheduling problems. As a group they are much more able to work around a 9-5 work schedule.

2. Students with motivation and academic performance issues are grouped with similar students. Often these students did not participate in the past because other team members would not let them, or their participation was not required. This places the students in a situation 
where there are no barriers to their participation. Many students 'bloom' in these teams. Although these teams would be expected to perform poorly, they rarely do so.

3. Abrasive students should be grouped on a single team. In many cases these students are misunderstood because of strong personality traits. At the best, grouping these individuals will allow them to soften their ways. At worst this reduces the problems to one team. In the past these individuals were distributed over multiple teams, creating multiple teams with problems.

4. The remaining students are grouped into teams to evenly distribute their skills. Ideally those with leadership talent or maturity are distributed among the teams.

Please note that the common academic approach is to only use the third step and blend the teams to distribute strengths and weaknesses evenly. However that approach only serves to create friction and reinforce problems such as those listed below.

i) Students who work full time during the day time are generally available in the evenings and weekends only. Placing these students on teams with full time students leads to continuous aggravation about scheduling. Creating teams of only full time students actually allows them to align their schedules and reduce conflict.

ii) A single student with an abrasive personality can poison a team. It is often better to have one team of 5 abrasive students that fights among themselves rather than 5 teams fighting. In a perverse way this also allows some of these students to "look in a mirror".

iii) Unmotivated students are often spread through teams to simply help them get through. This often creates a number of teams that are upset with one of their team mates. However when they are grouped on teams with others who are unmotivated they regularly rise to the challenge. Some of my best projects have come from 'unmotivated' teams.

The process of categorizing and then grouping students may seem distasteful, but when done carefully it can enhance the pedagogical experience. However the instructor is well advised to ignore the groupings after they have been made. Once the teams have been set, all teams are equal.

\section{Peer Evaluations}

The peer evaluation form shown in appendix B is used for junior level mechanical and product design and manufacturing engineering students. Similar forms are used for other upper level courses including senior project. The peer evaluation is normally administered the first time in the middle of the semester. At that time it allows the instructor to assess the team culture on an individual basis, and it allows the students to reflectively consider the team. The second and last time the peer evaluation is used is at the conclusion of the project. These are used to adjust individual student grades.

As expect, the numerical values on the form are the least important indicator. The best indicator of performance is the comments and the question "would you hire this person?" 


\section{The Outcomes}

The method for selecting teams described in this paper has been refined over a decade by a number of faculty teaching project oriented courses. Courses using these methods normally frequently have project success rates of $100 \%$. When similar projects have been done in the past with self selected teams the success rate was rarely perfect. For example, the EGR 345 class in 2001 used teams that were not grouped using this method. They were expected to design a (mechanical only) mechanism to extend and shoot a small projectile at a target. Of 13 teams, 10 finished the project successfully. The EGR 345 class in 2006 conducted a much more complex design - pairs of robots that would work in concert against opponents to shoot balls and defend goals automatically using

microcontrollers. The teams were grouped using the methods described in this paper, and all teams were successful. At the end of the course 37 peer evaluations were submitted for 6 teams. In response to the question "Would you hire this person?", 5 out of 37 students received a single negative evaluation, and 3 students received more than one, none of these were unanimous. In other words fewer than one in ten peer reviews was negative.

Although these methods do take additional time at the beginning of a course, they greatly reduce the time commitment during the course to deal with problem teams. For example, in one course I normally have 10 teams of 5-7. In the past it would be normal to have 4 dysfunctional teams per semester. Now, the rate is typically one. The process is much more enjoyable for me and the students.

Another welcome outcome is that the students who are normally having problems in groups find themselves in teams where they can thrive. As a result many of them produce surprising results. It is inspiring when a team that (on paper) should have been easily defeated has the strongest showing.

\section{Bibliography}

1. Jendrucko, R. J., Wasserman, J.F., "Optimizing Student Learning in a BME Capstone Design Course Sequence", ASEE Annual Meeting, 2004.

2. Jack, H., Ray, J., Farris, J., "Design and Build Projects as a Curriculum Thread", ASEE North Central Section Conference, Kalamazoo, MI, March 2004.

3. Berens, L.V., Cooper, S.A., et. al., "Quick Guide to the 16 Personality Types in Organizations: Understanding Personality Differences in the workplace", Telos Publishers, 2002.

4. Fried, L., "Team Size and Productivity in Systems Development", Information Systems Management, Vol. 8, Issue 3, pg. 27, Summer 1991. 
Appendix A - Self Evaluations

\section{Skills Self Evaluation}

\section{Your Name:}

\section{none}

Hands-on Mechanical:

The ability to build components with wood, plastic, metal or other materials.

Hands-on Electrical:

Basic wiring skills, soldering, etc.

Hands-on Computer Usage:

CAD, Spreadsheets, creating web pages, etc.

Hands-on Computer Application:

Programming and computer interfacing

Mathematical Problem Solving:

Ability to formulate and solve complex problems

Writing:

Layout and write complex documents

Teamwork Skills:

The ability to work with others in a team environment.

\section{Leadership Skills:}

The ability to act as a role model that teammates will follow.

\section{Design Skills:}

Work in unstructured/semistructured problem solving.

Personal/Technical Strengths:

Personal/Technical Weaknesses:

People you would like to work with:

People you would NOT like to work with:

Other Commitments (courses, work, etc. - give hours for each) $\begin{array}{lllll}1 & 2 & 3 & 4 & 5\end{array}$

$\begin{array}{lllll}1 & 2 & 3 & 4 & 5\end{array}$

$\begin{array}{lllll}1 & 2 & 3 & 4 & 5\end{array}$

$\begin{array}{lllll}1 & 2 & 3 & 4 & 5\end{array}$

$\begin{array}{lllll}1 & 2 & 3 & 4 & 5\end{array}$

$\begin{array}{lllll}1 & 2 & 3 & 4 & 5\end{array}$

$\begin{array}{lllll}1 & 2 & 3 & 4 & 5\end{array}$

$\begin{array}{lllll}1 & 2 & 3 & 4 & 5\end{array}$

$\begin{array}{lllll}1 & 2 & 3 & 4 & 5\end{array}$

5

5

5


Appendix B - Peer Evaluations

EGR 101/345 Project Peer Evaluation

Your Name:

Team Number:

Person Being Evaluated:

good

poor

Communicates well: $\quad 1 \underset{\text { Did the teammatc return e-mails and other forms of communication promply'y? Could the teammate }}{2} \quad \begin{array}{lll}2 & 4\end{array}$

understand, explain and evaluate the technical aspects of the project in a clear concise manner?

\section{Works in team environment: $\begin{array}{llllll}1 & 2 & 3 & 4 & 5\end{array}$}

Did your teammate come to meetings on time? Did the teammate participate in all aspects of the project? How much did the teammate's efforts contribute to the overall success of the project?

\section{Meets deadlines: $\quad \begin{array}{lllll}1 & 2 & 3 & 4 & 5\end{array}$}

Did you teammate complete individual tasks on time? Did the teammate keep the project progressing forward in a timely manner with a consistent effort throughout the project or was the teammate only available when the team was in trouble?

\section{$\begin{array}{llllll}\text { Quality of work: } & 1 & 2 & 3 & 4 & 5\end{array}$}

Was you r teammate willing to accept and carry out individual tasks on time? How well were these

individual tasks carried out? Did your teammate do his or her fair share of the work?

$\begin{array}{lllll}\text { Overall: } & 1 & 2 & 3 & 4\end{array}$

Would you hire this person: yes / no

Other Comments: 